\title{
Dimensões e Indicadores da Qualidade de Vida e do Bem-Estar no Trabalho
}

\author{
Cleide Aparecida da Silva ${ }^{1}$ \\ Maria Cristina Ferreira \\ Universidade Salgado de Oliveira
}

\begin{abstract}
RESUMO - Investigou-se a influência de dimensões da qualidade de vida e bem-estar no trabalho (salários e benefícios; oportunidades de uso e desenvolvimento das próprias competências; condições físicas e de segurança no ambiente de trabalho; relacionamento e comunicação entre supervisores e empregados; relacionamento interpessoal com colegas de trabalho) sobre seus indicadores (comprometimento organizacional afetivo, satisfação no trabalho, afetos positivos dirigidos ao trabalho). Duzentos e oitenta e quatro empregados do setor elétrico estatal responderam a escalas de avaliação dos diferentes construtos investigados. As oportunidades de uso e desenvolvimento das próprias competências foram o principal preditor positivo dos três indicadores considerados. Tais oportunidades caracterizam-se como um recurso motivacional do contexto laboral que influencia positivamente os indicadores da qualidade de vida e bem-estar no trabalho.
\end{abstract}

Palavras-chave: qualidade de vida no trabalho, bem-estar no trabalho, saúde no trabalho

\section{Dimensions and Indicators of Quality of Life and Well-Being at Work}

\begin{abstract}
The influence of dimensions of quality of life and well-being at work (salaries and benefits; opportunities of using and developing one's own skills; physical and safety conditions at work; relationship and communication between supervisors and employees; interpersonal relationship between job colleagues) on its indicators (affective organizational commitment, job satisfaction and positive affects toward work) was investigated. Two hundred and eight four employees from the state electricity sector responded to scales designed for evaluating the constructs that take part in the investigation. The opportunities of using and developing one's own skills were the main predictor of all three indicators investigated. Those opportunities can be seen as a motivational job resource that influences positively the quality of life and well-being at work.
\end{abstract}

Key words: quality of work life, well-being at work, occupational health

Ao final do século XX, as mudanças nas organizações e na natureza do trabalho se aprofundaram, em decorrência, sobretudo, da globalização, das fusões e reestruturações, da aceleração do desenvolvimento tecnológico e da necessidade de as empresas sobreviverem em um mercado cada vez mais competitivo. Como forma de responder a essas demandas, e preocupadas com a competitividade e o cumprimento da legislação vigente, as organizações vêm investindo cada vez mais na melhoria das condições de trabalho e da qualidade de vida e bem-estar de seus membros, de modo a minimizar os efeitos deletérios que o contexto organizacional e do trabalho podem provocar nesses indivíduos.

A qualidade de vida no trabalho tem sido por vezes abordada sob a forma de definições que destacam o modo pelo qual ela é percebida pelo indivíduo e, por vezes, mediante o uso de definições que enfatizam as características do local de trabalho. No primeiro caso, a ênfase recai nos aspectos subjetivos associados aos sentimentos e à satisfação com o trabalho e seu entorno, enquanto, no segundo caso, são contempladas as condições de trabalho, a tecnologia, os equipamentos e o ambiente físico, dentre outros aspectos (González, Peiró, \& Bravo, 1996). Em outras palavras, a qualidade de vida no trabalho tem sido relacionada, por

1 Endereço para correspondência: Universidade Salgado de Oliveira - UNIVERSO, Rua Rio Grande do Sul 930/501, Ivaiporã, PR, CEP: 86870-000.E-mail: cleideas@furnas.com.br um lado, a uma gama de práticas organizacionais e, por outro, aos efeitos de determinadas condições do ambiente da organização sobre a saúde e bem-estar do indivíduo (Bowditch \& Buono, 2002).

O bem-estar no trabalho, por sua vez, tem sido utilizado para designar as consequências subjetivas da qualidade de vida no trabalho. Nesse sentido, van Horn, Taris, Schaufeli e Scheurs (2004) afirmam que o bem-estar no trabalho consiste no resultado das avaliações positivas que o indivíduo faz sobre as diferentes características do ambiente laboral, contemplando componentes cognitivos, afetivos, motivacionais, psicossomáticos e comportamentais dos indivíduos. Já de acordo com Paz (2004), o bem-estar decorre do fato de os indivíduos sentirem que suas necessidades e desejos são satisfeitos a partir do desempenho de seus papéis organizacionais, manifestando-se, dessa forma, por meio de sentimentos e cognições de gratificação.

A análise das várias definições que vêm sendo oferecidas na literatura para os construtos qualidade de vida e bem-estar no trabalho evidencia, no entanto, que ora eles são tratados como sinônimos, ora como conceitos distintos. Reconhecendo a similaridade conceitual entre esses termos, o presente trabalho irá considerá-los como diferentes denominações para um mesmo fenômeno associado às percepções subjetivas sobre as condições do contexto laboral e sobre suas consequências para as atitudes, sentimentos e afetos dos indivíduos acerca de seu trabalho. Nesse sentido, irá 
adotar a palavra dimensões, para se referir às condições do contexto laboral associadas à qualidade de vida e bem-estar no trabalho, e o termo indicadores, para designar as atitudes, sentimentos e afetos sobre o trabalho decorrentes de tais condições laborais.

Ao longo dos últimos 40 anos, diferentes modelos teóricos (Hackman \& Oldham, 1975; Nadler \& Lawler III, 1983; Walton, 1973; Warr, 1987; Westley, 1979) vêm sendo desenvolvidos com o intuito de caracterizar as dimensões da qualidade de vida e bem-estar no trabalho. Analisando tal literatura, os presentes autores verificaram que, em função de sua semelhança conceitual, essas dimensões podiam ser sistematizadas em um conjunto de oito categorias básicas: salário e benefícios; oportunidades de desenvolvimento e uso das próprias competências; natureza da tarefa; relacionamento interpessoal; condições físicas do ambiente de trabalho; equilíbrio trabalho-família; observância dos princípios constitucionais; imagem da organização junto à sociedade.

Contudo, cinco dessas categorias têm sido mais frequentemente adotadas nas investigações destinadas a avaliar a incidência relativa da qualidade de vida e bem-estar no trabalho. São elas: salário/compensação e benefícios (Asfora \& Dias, 2006; Considini \& Callus, 2002; Leite Filho \& Almeida, 2005; Pizzoli, 2005; Tolfo \& Piccini, 2001); oportunidades de uso e desenvolvimento das próprias competências (Asfora \& Dias, 2006; Pizzoli, 2005; Tolfo \& Piccini, 2001); natureza da tarefa, no que tange a sua variedade, clareza de metas e grau de autonomia (Warr, 1987; Wilson, DeJoy, Vandenberg, Richardson, \& McGrath., 2004); condições físicas e de segurança no ambiente de trabalho (Asfora \& Dias, 2006; Considini \& Callus, 2002; Leite Filho \& Almeida, 2005; Lewchuck, Stewart, \& Yates, 2001; Pizzoli, 2005); relacionamento interpessoal entre colegas de trabalho (Asfora \& Dias; Considini \& Callus, 2002; Leite Filho \& Almeida, 2005). Apoiando-se nos autores citados, essas cinco categorias foram também inicialmente escolhidas para caracterizar as dimensões da qualidade de vida e bem-estar no trabalho a serem utilizadas na presente pesquisa.

Atendo-se aos indicadores da qualidade de vida e bem-estar no trabalho, nota-se que, durante muito tempo, os modelos teóricos não variaram muito quanto a esse aspecto. Assim é que, na década de 1970, a maioria dos autores (Hackman \& Oldham, 1975; Walton, 1973; Westley 1979) trabalhou prioritariamente com a satisfação no trabalho como indicador da qualidade de vida e bem-estar no trabalho. Mais recentemente, porém, os estudos de Warr (1987) e de van Horn et al. (2004) proporcionaram avanços nessa questão, ao aumentar o escopo inicialmente atitudinal da qualidade de vida e bem-estar no trabalho, para nele incluir, também, os afetos dirigidos ao trabalho.

Warr (1987) preconiza que o bem-estar no trabalho se manifesta por meio de aspectos cognitivos e afetivos. Os aspectos cognitivos referem-se à satisfação no trabalho em geral, bem como à satisfação com os supervisores, colegas de trabalho e pagamento, enquanto os afetivos dizem respeito às respostas emocionais dirigidas ao contexto do trabalho, que se expressam em sentimentos de ansiedade, entusiasmo, depressão, conforto, entre outros. Já van Horn et al. (2004), ao descreverem o bem-estar ocupacional, consideram os aspectos afetivo (bem-estar afetivo, falta de exaustão emo- cional e comprometimento afetivo), profissional (autonomia, aspiração e competência profissional), social (falta de despersonalização), cognitivo (capacidade de se concentrar) e psicossomático (ausência de queixas psicossomáticas). No entanto, esses autores enfatizam que o aspecto afetivo constitui o cerne do bem-estar laboral.

Fundamentando-se em tais considerações e nas manifestações de bem-estar afetivo propostas por Warr (1987) e van Horn et al. (2004), a presente investigação optou por trabalhar com os seguintes indicadores afetivos da qualidade de vida e bem-estar no trabalho: comprometimento organizacional, satisfação no trabalho e afetos positivos dirigidos ao trabalho. O comprometimento organizacional afetivo caracteriza-se por um vínculo afetivo do indivíduo com a organização, que se expressa na identificação com seus valores e missão (Meyer \& Allen, 1997). A satisfação no trabalho, por sua vez, pode ser vista como uma resposta afetiva decorrente de avaliações positivas acerca do trabalho (Locke, 1976; Brief \& Roberson, 1989). Já os afetos positivos dirigidos ao trabalho consistem em respostas emocionais positivas que os indivíduos dirigem a seu contexto de trabalho (Ferreira, Silva, Fernandes, \& Pacheco, 2008).

As pesquisas destinadas a investigar o poder preditivo de diferentes dimensões da qualidade de vida e do bem-estar no trabalho em alguns de seus indicadores ainda são incipientes. Assim é que, nas bases de dados pesquisadas (Banco de Teses e Dissertações da CAPES, Scielo, Pepsic e Psychinfo), usando-se as palavras-chave qualidade de vida no trabalho e bem-estar no trabalho, foram localizados somente três estudos estrangeiros e dois nacionais sob essa perspectiva. Tais estudos mostraram que os valores organizacionais (Covacs, 2006), o suporte organizacional (Covacs, 2006), as percepções de justiça (Chiuzi, 2006; Covacs, 2006), o grau de dificuldade do trabalho, a variedade do trabalho, a organização do trabalho, as mudanças de tarefa (Schouteten \& Witte, 1999), o clima psicológico (Carvalho, 2007), o sistema de compensação e benefícios, o comprometimento do supervisor e o equilíbrio vida e trabalho (Huang, Lawler, \& Yi-Lei, 2007) constituem preditores positivos do bem- estar no trabalho.

O exame de tais estudos revela, porém, que nenhum dos estudos nacionais (Chiuzi, 2006; Covacs, 2006) deteve-se na averiguação do poder preditivo das cinco dimensões de qualidade de vida e bem-estar no trabalho anteriormente mencionadas sobre seus indicadores. Outrossim, em que pese o fato de alguns dos estudos estrangeiros terem abordado algumas dessas dimensões, nenhum deles examinou o impacto conjunto de todas as cinco em indicadores da qualidade de vida e bem-estar no trabalho. Justificam-se, assim, pesquisas brasileiras adicionais sobre o assunto, capazes de avaliar o impacto diferencial de um conjunto de dimensões da qualidade de vida e bem-estar no trabalho sobre seus indicadores. Nesse sentido, a presente investigação se orientou pelo objetivo geral inicial de investigar o poder preditivo de cinco dimensões da qualidade de vida e bem-estar no trabalho (salários e benefícios; oportunidades de uso e desenvolvimento das próprias competências; natureza da tarefa; condições físicas e de segurança no ambiente de trabalho; relacionamento interpessoal entre colegas de trabalho) sobre três indicadores de tal construto: compro- 
metimento organizacional afetivo, satisfação no trabalho e afetos positivos dirigidos ao trabalho.

Cumpre ressaltar, porém, que, após a realização da validação fatorial do instrumento desenvolvido para a avaliação das dimensões da qualidade de vida e bem-estar no trabalho, foi necessário realizar algumas modificações no conjunto de dimensões inicialmente preconizadas. Outrossim, a investigação é de caráter exploratório, razão pela qual não foram formuladas hipóteses sobre a natureza das relações investigadas.

O contexto organizacional escolhido para a realização da pesquisa foi uma empresa do setor elétrico nacional, subsidiária da Eletrobrás. A empresa opera em 12 estados brasileiros e no Distrito Federal, tendo um efetivo de 4500 empregados. Ela possui um Programa de Qualidade de Vida que tem por objetivo proporcionar maior satisfação e bem-estar físico, sócio-emocional, espiritual e intelectual a seus empregados. As principais atividades desenvolvidas pelo programa são: atividades físicas; orientação nutricional; palestras motivacionais; atividades de relaxamento, meditação e autoconhecimento; atividades culturais. O principal motivo de escolha da empresa referida foi a maior facilidade de acesso aos empregados, em função de uma das autoras do presente trabalho pertencer à organização.

\section{Método}

\section{Participantes}

Foram distribuídos cerca de 1000 questionários aos empregados lotados nas unidades da empresa situadas nos Estados do Paraná, São Paulo, Minas Gerais, Goiás e Rio de Janeiro, bem como no Distrito Federal, em função de uma das autoras possuir contatos nessas unidades da empresa. Desse total, foram devolvidos 306 , o que correspondeu a uma taxa de devolução de 33,0 \%. Dentre eles, 22 questionários foram excluídos, por não terem sido preenchidos em sua totalidade, ficando, assim, a amostra final composta por 284 empregados. O sexo desses indivíduos foi predominantemente masculino $(68,2 \%)$, com idades variando de 19 a 67 anos (média de 44,22 anos e desvio padrão de 10,24 anos). Quanto ao estado civil, a maioria era casada (67,0\%), enquanto, no que diz respeito à escolaridade, grande parte da amostra $(61,0 \%)$ possuía nível superior completo, com uma parcela desse total tendo inclusive pós-graduação stricto sensu. No que tange aos salários, a maioria da amostra $(71,1 \%)$ recebia acima de seis salários mínimos. O tempo de trabalho na empresa variou de um a 37 anos, com tempo médio de 16,37 anos e desvio padrão de 10,31. Atendo-se, por fim, à natureza do cargo dos participantes, observou-se um equilíbrio entre os ocupantes de cargos de nível técnico e de nível superior, com um percentual em torno de $40,0 \%$ em ambos os casos.

\section{Instrumentos}

Para a avaliação das dimensões da qualidade de vida e bem-estar no trabalho foi utilizado um questionário elabo- rado especificamente para a presente pesquisa, com base em instrumentos previamente existentes na literatura. A primeira versão do instrumento compôs-se de 108 itens, distribuídos por cinco dimensões: salários e benefícios, oportunidades de uso e desenvolvimento das próprias competências, relacionamento interpessoal no trabalho, condições físicas do ambiente de trabalho e natureza da tarefa. Esses itens foram, em seguida, discutidos e analisados por um grupo de alunos de mestrado em psicologia, como forma de refiná-los e reduzi-los. Nesse sentido, o questionário utilizado na coleta de dados ficou composto por 60 afirmativas, a serem respondidas em escalas de seis pontos, variando de discordo fortemente (1) a concordo fortemente (6), de acordo com a opinião do respondente sobre o grau em que cada uma das afirmativas aplicava-se à sua empresa. Exemplos desses itens são: Meus superiores diretos reconhecem minha dedicação ao trabalho; Trabalho em um ambiente seguro. As informações referentes ao processo de verificação das evidências de validade do referido instrumento são apresentadas na primeira parte da seção de resultados.

Para a avaliação da satisfação no trabalho, foi utilizada a Escala de Satisfação Geral no Trabalho (Silva \& Ferreira, 2009), que é unifatorial e compõe-se de cinco itens, a serem respondidos em escalas de seis pontos, variando de concordo fortemente (6) a discordo fortemente (1), de acordo com o grau de satisfação do respondente em relação a seu trabalho. São exemplos de tais itens: Sinto-me satisfeito com meu trabalho atual; Se eu tivesse que escolher um trabalho, eu escolheria o meu. No estudo citado, o coeficiente de consistência interna dessa escala, calculado pelo coeficiente Alfa de Cronbach, foi igual a 0,80 . Na presente investigação, tal coeficiente foi igual a 0,90 .

$\mathrm{O}$ comprometimento organizacional afetivo foi avaliado pela Escala de Comprometimento Afetivo de Meyer e Allen (1997), em versão adaptada para o Brasil por Ferreira et al. (2002). A referida escala consta de seis itens, a serem respondidos em escalas de seis pontos, variando de discordo totalmente (1) a concordo totalmente (6), de acordo com os sentimentos manifestados pelo respondente em relação à sua organização. Exemplos de tais itens são: Sinto os problemas da empresa como se fossem meus; Sinto-me emocionalmente ligado à empresa. No estudo de validação inicial, a escala obteve um índice de consistência interna igual a 0,85 , calculado pelo Alfa de Cronbach. Na atual investigação, esse coeficiente foi de 0,91 .

Os afetos positivos dirigidos ao trabalho foram avaliados pela sub-escala de afetos positivos da Escala de Afetos no Trabalho (ESAFE), de autoria de Ferreira et al. (2008), a qual consta de 14 itens, a serem respondidos em escalas de seis pontos, variando de nunca (1) a sempre (6), de acordo com a frequência de emoções vivenciadas no ultimo mês em relação ao trabalho. São exemplos desses itens: Entusiasmado; Orgulhoso. O índice de consistência interna da escala, no estudo original, calculado pelo Alfa de Cronbach, foi de 0,93 e, no presente estudo, foi igual a 0,95 . Foram incluídas, ainda, no instrumento de coleta de dados, perguntas destinadas à coleta de informações sócio-demográficas sobre os participantes e o termo de consentimento livre e esclarecido. 


\section{Procedimentos}

Após a submissão e aprovação do projeto pelo Comitê de Ética em Pesquisa da instituição das autoras, foi encaminhada à superintendência de recursos humanos da organização pesquisada uma solicitação formal para a realização da investigação. No entanto, a autorização da pesquisa por meios institucionais foi negada, com a alegação de que os empregados tinham sido submetidos recentemente a uma pesquisa de clima organizacional. Não houve, porém, oposição a que os empregados fossem contatados individualmente e convidados a participar da pesquisa. Nesse sentido, um dos autores usou sua rede de contatos na organização para enviar os questionários por e-mail, por correio ou mesmo entregá-los pessoalmente. Em todos os casos, os participantes receberam inicialmente esclarecimentos sobre os objetivos da pesquisa e sobre seu caráter sigiloso. Em seguida, os que concordaram em colaborar foram solicitados a preencher os questionários, em tempo livre. Nesse sentido, a amostra utilizada na pesquisa foi de conveniência.

Para a análise dos dados, verificou-se inicialmente a validade fatorial da Escala de Dimensões da Qualidade de Vida e Bem-estar no Trabalho, mediante a realização de procedimentos de análise fatorial exploratória. Em seguida, foram calculadas as estatísticas descritivas (médias e desvios padrão) das diferentes escalas do estudo, bem como os coeficientes de correlação entre elas. Posteriormente, com o intuito de se verificar a possibilidade de a análise de regressão linear múltipla ser adotada na análise dos dados, foi necessário inspecionar se eles atendiam aos pressupostos desse tipo de análise (Tabachnick \& Fidell, 2001). Por fim, foram realizadas três análises de regressão múltipla linear, para se averiguar o poder preditivo das cinco dimensões da qualidade de vida e bem-estar no trabalho sobre o comprometimento organizacional afetivo, a satisfação no trabalho e os afetos positivos dirigidos ao trabalho.

\section{Resultados}

\section{Validade fatorial da Escala de Dimensões da Qualidade de Vida e Bem-Estar no Trabalho}

No processo de validação fatorial da Escala de Dimensões Organizacionais da Qualidade de Vida e Bem-Estar no Trabalho, foram inicialmente verificados os pressupostos da análise fatorial, por meio da medida de Kaiser-Meyer-Olkin (KMO), que apresentou resultado igual a 0,94, indicando, assim, a adequação dos dados à análise. De modo semelhante, o teste de esferecidade de Bartlett foi significativo $\left(\chi^{2}=10.765,72\right.$; $p<0,001)$, numa evidência de que as correlações entre os itens permitiam a realização da análise fatorial. Nesse sentido, a matriz de intercorrelações entre os itens foi inicialmente submetida à análise dos componentes principais, que extraiu 11 fatores com valores próprios (eingenvalues) maiores que 1, responsáveis por $64,3 \%$ da variância total do instrumento. Adicionalmente, o teste gráfico (scree plot) revelou um número de cinco a sete fatores interpretáveis.
Nesse sentido, foram realizadas análises fatoriais adicionais, por meio do método dos eixos principais e rotação oblíqua, com solução antecipada de cinco a sete fatores. Tais análises evidenciaram que a solução de cinco fatores foi a que melhor representou a estrutura interna de escala, tendo explicado $47,1 \%$ da variância total do instrumento. Nela, foram retidos os itens que apresentaram cargas fatoriais superiores a 0,30 em um único fator e que demonstraram similaridade conceitual com os demais itens do fator (Tabela 1).

O Fator 1 compôs-se de nove itens e foi denominado de relacionamento e comunicação entre supervisores e empregados, em função de conter afirmativas associadas à natureza das relações interpessoais entre chefes e subordinados e à forma com que a comunicação entre eles ocorre. O Fator 2 ficou com nove itens relacionados às condições físicas e de segurança do ambiente de trabalho. Com seis itens, o Fator 3 destinou-se a avaliar a percepção dos empregados em relação aos salários e aos benefícios oferecidos pela empresa. Composto de nove itens, e intitulado de oportunidades de uso e desenvolvimento das próprias competências, o Fator 4 tem como objetivo identificar em que grau os empregados percebem que a empresa lhes proporciona meios de se desenvolver profissionalmente e fazer uso de suas competências. O Fator 5, por fim, ficou com cinco itens e foi denominado de relacionamento interpessoal com os colegas de trabalho, por conter afirmativas associadas à qualidade das relações entre os empregados no ambiente de trabalho. Os índices de consistência interna dessas subescalas, calculados pelo coeficiente Alfa de Cronbach, foram, respectivamente, iguais a: 0,$90 ; 0,84 ; 0,86 ; 0,90 ; 0,78$.

Em síntese, a versão final da Escala de Dimensões Organizacionais da Qualidade de Vida e Bem-Estar no Trabalho ficou composta por cinco fatores. Das cinco categorias iniciais que nortearam a construção do instrumento, três obtiveram apoio empírico: salários e benefícios; oportunidades de uso e desenvolvimento das próprias competências; condições físicas e de segurança no ambiente de trabalho. O relacionamento interpessoal entre colegas de trabalho, por sua vez, subdividiu-se em duas diferentes categorias: relacionamento e comunicação entre supervisores e empregados e relacionamento interpessoal com os colegas de trabalho. Por fim, a categoria natureza da tarefa não recebeu apoio empírico. Desse modo, todas as análises subsequentes foram realizadas com a versão da escala composta por 38 itens, distribuídos nas cinco dimensões supramencionadas.

\section{Análises de regressão}

A Tabela 2 apresenta as médias e desvios padrão das diferentes escalas do estudo, bem como os coeficientes de correlação entre tais escalas. Na verificação do pressuposto da regressão associado à normalidade, a observação dos histogramas com a sobreposição da curva normal evidenciou que todas as variáveis apresentaram uma distribuição próxima à distribuição normal, razão pela qual não houve necessidade de transformação dos dados de nenhuma delas. Por outro lado, o diagrama de dispersão dos resíduos padronizados em relação aos escores preditos indicou o atendimento ao pressuposto da homocedasticidade. Não foi identificada, também, a 
Tabela 1. Cargas fatoriais dos itens da Escala de Dimensões da Qualidade de Vida e Bem-Estar no Trabalho

\begin{tabular}{|c|c|c|c|c|c|}
\hline Itens & F1 & F2 & F3 & F4 & F5 \\
\hline 2. Meus superiores diretos reconhecem minha dedicação ao trabalho & 0,60 & & & & \\
\hline $\begin{array}{l}\text { 8. A qualidade de minhas relações com meus superiores diretos são tão boas quanto eu gostaria } \\
\text { que elas fossem }\end{array}$ & 0,54 & & & & \\
\hline 13. Recebo informações claras sobre minhas atribuições & 0,71 & & & & \\
\hline 15. Meus superiores fazem uma avaliação justa de meu trabalho & 0,65 & & & & \\
\hline 20. Quando há mudanças em meu trabalho, elas são expostas claramente & 0,71 & & & & \\
\hline 36. Sou informado quando meu trabalho deixa a desejar & 0,61 & & & & \\
\hline 47. Meus superiores me dizem quando fiz um bom trabalho & 0,84 & & & & \\
\hline 48. Meus superiores diretos me dão instruções sobre como aprimorar a qualidade de meu trabalho & 0,82 & & & & \\
\hline 55. Posso dar opiniões nas decisões que afetam meu trabalho & 0,63 & & & & \\
\hline 12. Em minha empresa, dispomos de equipamentos adequados à realização de nossas tarefas & & 0,58 & & & \\
\hline 19. Em minha empresa, o espaço físico alocado para cada equipe de trabalho é adequado & & 0,48 & & & \\
\hline 22. Sinto-me fisicamente seguro em meu trabalho & & 0,40 & & & \\
\hline 35. As condições de trabalho que tenho são satisfatórias & & 0,50 & & & \\
\hline 40. Trabalho em um ambiente seguro & & 0,63 & & & \\
\hline 49. Em minha empresa, as condições de higiene são adequadas & & 0,60 & & & \\
\hline 52. Em minha empresa, as condições físicas de ruído são adequadas & & 0,56 & & & \\
\hline 56. Em minha empresa, as condições físicas de iluminação são adequadas & & 0,64 & & & \\
\hline 57. Meu trabalho me permite manter uma boa saúde geral & & 0,60 & & & \\
\hline
\end{tabular}

Tabela 1. Cargas fatoriais dos itens da Escala de Dimensões da Qualidade de Vida e Bem-Estar no Trabalho (cont.)

\begin{tabular}{|c|c|c|c|c|c|}
\hline Itens & F1 & $\mathrm{F} 2$ & F3 & F4 & F5 \\
\hline 3. Meu salário é justo, se comparado aos salários de cargos semelhantes em outras empresas & & & 0,65 & & \\
\hline 11. Meu salário me permite proporcionar boas condições de vida à minha família & & & 0,58 & & \\
\hline 23. Os benefícios que recebo atendem às minhas necessidades & & & 0,39 & & \\
\hline 26. O salário que recebo é adequado às minhas competências profissionais & & & 0,74 & & \\
\hline 44. A empresa me oferece boas chances de promoção & & & 0,34 & & \\
\hline 53. Os benefícios da minha empresa constituem um verdadeiro salário indireto & & & 0,44 & & \\
\hline 1. Meu trabalho é bem diversificado & & & & 0,49 & \\
\hline 6. O trabalho que faço me desenvolve enquanto pessoa & & & & 0,46 & \\
\hline 27. Tenho chances de usar todas as minhas habilidades em meu trabalho & & & & 0,36 & \\
\hline 31. Tenho oportunidade de realizar tarefas complexas em meu trabalho & & & & 0,54 & \\
\hline 34. Meu trabalho é bastante criativo & & & & 0,58 & \\
\hline 38. Meu trabalho me possibilita progredir em minha carreira & & & & 0,47 & \\
\hline 42. Meu trabalho me coloca constantemente frente a desafios & & & & 0,66 & \\
\hline 50. Meu trabalho me permite aprimorar minhas competências profissionais & & & & 0,43 & \\
\hline 51. Em meu trabalho, estou sempre aprendendo coisas novas & & & & 0,48 & \\
\hline 4. Tenho bons amigos em meu trabalho & & & & & 0,50 \\
\hline 7. Costumo receber suporte de meus colegas quando tenho problemas pessoais & & & & & 0,53 \\
\hline 25. Meus colegas me ajudam, quando tenho dificuldades no trabalho & & & & & 0,49 \\
\hline $\begin{array}{l}\text { 43. Minhas relações com meus colegas de trabalho são tão boas quanto eu gostaria que elas } \\
\text { fossem }\end{array}$ & & & & & 0,54 \\
\hline 46. Sou respeitado por meus colegas de trabalho & & & & & 0,47 \\
\hline
\end{tabular}


Tabela 2. Médias, desvios padrões e coeficientes de correlação entre as dimensões e indicadores da qualidade de vida e bem-estar no trabalho

\begin{tabular}{|c|c|c|c|c|c|c|c|c|c|}
\hline Escalas & M & DP & 1 & 2 & 3 & 4 & 5 & 6 & 7 \\
\hline Oportunidade de uso das competências (1) & 4,08 & 0,98 & ----- & ----- & ----- & ----- & ----- & ----- & ----- \\
\hline Relacionamento com colegas (2) & 4,59 & 0,78 & $0,49 * *$ & ----- & ----- & ----- & ----- & ----- & ----- \\
\hline Salários e benefícios (3) & 3,86 & 1,07 & $0,57 * *$ & $0,32 * *$ & ----- & ----- & ----- & ----- & ----- \\
\hline Condições físicas e de segurança (4) & 4,57 & 0,77 & $0,48 * *$ & $0,45^{* *}$ & $0,49 * *$ & ----- & ----- & ----- & ----- \\
\hline $\begin{array}{l}\text { Relacionamento entre supervisores e } \\
\text { empregados (5) }\end{array}$ & 3,86 & 0,99 & $0,68 * *$ & $0,55^{* *}$ & $0,62 * *$ & $0,56^{* *}$ & ----- & ----- & ----- \\
\hline Satisfação no trabalho (6) & 4,17 & 1,22 & $0,71^{* *}$ & $0,42 * *$ & $0,54 * *$ & $0,48^{* *}$ & $0,64 * *$ & ----- & ----- \\
\hline Afetos positivos sobre o trabalho (7) & 4,31 & 1,16 & $0,69 * *$ & $0,41 * *$ & $0,53^{* *}$ & $0,42 * *$ & $0,63 * *$ & $0,73^{* *}$ & ----- \\
\hline Comprometimento organizacional afetivo (8) & 4,33 & 1,00 & $0,61 * *$ & $0,38 * *$ & $0,54 * *$ & $0,40 * *$ & $0,51 * *$ & $0,70 * *$ & $0,66^{* *}$ \\
\hline
\end{tabular}

$* p<0,05 \quad * * p<0,01$

presença de outliers, já que não foram encontrados valores de $\mathrm{z}$ iguais ou acima de 3,29 em nenhuma das escalas. No teste de linearidade, os scaterplots demonstraram que as relações entre todas as variáveis independentes e dependentes eram lineares. Adicionalmente, o atendimento a tal pressuposto foi verificado mediante a inspeção dos valores de assimetria das variáveis, que foram todos menores que 1, numa indicação de que as mesmas não apresentaram problemas de linearidade. No que tange à multicolinearidade, constatou-se que nenhuma das correlações entre as variáveis preditoras foi maior que 0,90, o que demonstra a não existência de multicolinearidade. Por outro lado, após a efetivação da análise de regressão, observou-se que os valores de tolerância foram todos acima de 0,20 , enquanto os de VIF apresentaram-se todos abaixo de 4, confirmando, assim, tal pressuposto.

A análise de regressão múltipla com o comprometimento organizacional afetivo como variável critério demonstrou que o conjunto de variáveis preditoras que entrou na equação explicou $43 \%$ da variância de tal variável critério. No entanto, somente as oportunidades de uso e desenvolvimento das próprias competências e os salários e benefícios se destaca- ram como preditores positivos e significativos do comprometimento organizacional afetivo, com a primeira variável demonstrando maior poder preditivo que a segunda (Tabela 3).

Tomando como variável critério a satisfação no trabalho, foi observado que o conjunto de variáveis que entrou na equação foi responsável por $55 \%$ da variância da variável critério. Contudo, apenas as oportunidades de uso e desenvolvimento das próprias competências e o relacionamento e comunicação entre supervisores e empregados constituíram-se em preditores positivos e significativos da satisfação do trabalho (Tabela 3), com a primeira variável apresentando novamente maior poder preditivo que a segunda.

Na predição dos afetos positivos dirigidos ao trabalho, o conjunto de variáveis integrantes do modelo testado foi responsável por $52 \%$ da variância da variável critério. Dentre elas, porém, somente as oportunidades de uso e desenvolvimento das próprias competências, o relacionamento e comunicação entre supervisores e empregados e os salários e benefícios se constituíram em preditores positivos e significativos dos afetos positivos dirigidos ao trabalho (Tabela 3 ), com a primeira delas apresentando o maior poder preditivo.

Tabela 3. Análise de regressão múltipla linear das cinco dimensões da qualidade de vida e bem-estar no trabalho sobre seus três indicadores

\begin{tabular}{|c|c|c|c|}
\hline \multirow{3}{*}{$\begin{array}{l}\text { Dimensões da qualidade de vida e } \\
\text { bem-estar no trabalho }\end{array}$} & \multicolumn{3}{|c|}{ Indicadores da qualidade de vida e bem-estar no trabalho } \\
\hline & $\begin{array}{c}\text { Comprometimento organizacio- } \\
\text { nal afetivo }\end{array}$ & Satisfação no trabalho & $\begin{array}{c}\text { Afetos positivos dirigidos } \\
\text { ao trabalho }\end{array}$ \\
\hline & $\beta$ & $\beta$ & $\beta$ \\
\hline \multirow[t]{2}{*}{ Oportunidades de uso das competências } & & & $044 * * *$ \\
\hline & $0,40 * * *$ & $0,46^{* * *}$ & $0,44 \cdots$ \\
\hline \multirow[t]{2}{*}{ Relacionamento com colegas } & 0,08 & & 003 \\
\hline & & 0,01 & 0,03 \\
\hline Salários e benefícios & $0,27 * * *$ & 0,10 & $0,12 *$ \\
\hline $\begin{array}{l}\text { Condições físicas e de segurança no } \\
\text { trabalho }\end{array}$ & 0,03 & 0,09 & 0,00 \\
\hline $\begin{array}{l}\text { Relacionamento entre supervisores e } \\
\text { empregados }\end{array}$ & 0,00 & $0,20 * *$ & $0,24 * * *$ \\
\hline$R^{2}$ ajustado & 0,43 & 0,55 & 0,52 \\
\hline$F$ & $43,60 * * *$ & $69,73 * * *$ & $62,62 * * *$ \\
\hline
\end{tabular}

$* p<0,05 * * p<0,01 \quad p<0,001$ 


\section{Discussão}

A presente pesquisa investigou o poder preditivo de cinco dimensões da qualidade de vida e bem-estar no trabalho (salários e benefícios; oportunidades de uso e desenvolvimento das próprias competências; condições físicas e de segurança no ambiente de trabalho; relacionamento e comunicação entre supervisores e empregados; relacionamento interpessoal com os colegas de trabalho) em três indicadores desse construto: comprometimento organizacional afetivo, satisfação no trabalho e afetos positivos dirigidos ao trabalho.

Os resultados obtidos demonstraram que as oportunidades de uso e desenvolvimento das próprias competências caracterizaram-se como um preditor positivo e significativo dos três indicadores da qualidade de vida e bem-estar no trabalho aqui considerados. Foi verificado, assim, que a autonomia na tomada de decisões e no uso das próprias competências e criatividade possibilita melhor qualidade de vida e bem-estar no trabalho, em virtude de propiciar que os empregados demonstrem maior comprometimento afetivo com a organização, sintam-se mais satisfeitos com o seu trabalho e dirijam a ele mais afetos positivos.

Tais achados podem ser vistos como uma confirmação dos anteriormente obtidos por Shouteten e Witte (1999), que verificaram que a variedade do trabalho caracterizava-se como um preditor positivo do bem-estar, na medida em que, na realização de trabalhos que envolvem múltiplas tarefas, o empregado tem maiores oportunidades de usar suas habilidades e competências. Por outro lado, eles encontram sustentação teórica nos modelos de Hackman e Oldham (1975), Walton (1973) e Warr (1987). Nesse sentido, esses dois últimos autores assinalam que a detenção de maior autonomia e controle sobre o próprio trabalho, isto é, o fato de os empregados poderem lançar mão de suas habilidades ao desempenharem suas tarefas, na busca de metas que lhe instigam e desafiam, caracteriza-se como uma das importantes dimensões da qualidade de vida e bem-estar no trabalho. De modo semelhante, Hackman e Oldham (1975) sinalizam que o maior grau de autonomia no trabalho desperta sentimentos de que o indivíduo é pessoalmente responsável pelas consequências do trabalho que executa, o que terá como resultado maior grau de satisfação no trabalho.

Outra dimensão a impactar os indicadores da qualidade de vida e bem-estar no trabalho foi o relacionamento e comunicação entre supervisores e empregados, que contribuiu positivamente para a explicação da satisfação no trabalho e dos afetos positivos a ele dirigidos, mas não do comprometimento organizacional afetivo. Esses dados confirmam os de Carvalho (2007), que também observou que o apoio do supervisor predisse positivamente a satisfação no trabalho. Segundo Walton (1973), o respeito dos superiores à liberdade de expressão dos empregados, isto é, o fato de os superiores permitirem que os empregados expressem seus pontos de vista sem temer represálias caracteriza-se como outra dimensão central da qualidade de vida e bem-estar no trabalho. Similarmente, Warr (1987) defende que todo e qualquer apoio dado pelos supervisores aos empregados consiste em um dos fatores responsáveis pelo bem-estar afetivo no trabalho.

Tais asserções foram integralmente confirmadas na presente pesquisa, no que tange à utilização da satisfação no trabalho e dos afetos positivos a ele dirigidos como indicadores da qualidade de vida e bem-estar no trabalho. No entanto, o suporte do supervisor não afetou o comprometimento organizacional, o que pode ser atribuído ao fato de tal indicador caracterizar-se como um tipo de atitude dirigida à organização (Meyer \& Allen, 1997). Nesse sentido, ela não chegaria a ser impactada pelos comportamentos do supervisor, em razão desses indivíduos serem em geral percebidos como um colega de trabalho que detém um cargo hierarquicamente superior, e não como um representante da organização (Cohen-Charash \& Spector, 2001).

Os salários e benefícios constituíram-se em preditores positivos e significativos do comprometimento organizacional afetivo e dos afetos positivos dirigidos ao trabalho. De acordo com Walton (1973), o salário caracteriza-se como um dos principais indicadores de uma compensação justa e adequada, característica por ele considerada como uma dimensão fundamental da qualidade de vida e bem-estar no trabalho e um dos principais motivos que levam a pessoa a procurar um emprego. De modo semelhante, Warr (1987) inclui em seu modelo, a disponibilidade financeira, isto é, o grau em que o empregado aufere recursos financeiros que the possibilitem manter um padrão de vida adequado, como uma das categorias responsáveis pelo bem-estar afetivo no trabalho.

Coerente com essas proposições teóricas, o presente estudo evidenciou que os salários e benefícios impactaram positivamente dois dos indicadores de qualidade de vida e bem-estar no trabalho, quais sejam o comprometimento organizacional afetivo e os afetos dirigidos ao trabalho. No entanto, eles não chegaram a impactar a satisfação no trabalho. Uma provável explicação para tal resultado pode ser a de que, ao contrário do que ocorre com o comprometimento organizacional, cujo foco é a organização (Meyer \& Allen, 1997), a satisfação tem como foco o contexto do trabalho (Brief \& Roberson, 1989). Nesse sentido, esta última não chegaria a sofrer as influências de políticas atinentes à organização, como é o caso dos salários e benefícios.

Resta, contudo, discutir os motivos pelos quais os afetos positivos dirigidos ao trabalho, que também têm como foco o contexto do trabalho (Ferreira et al., 2008), sofreram um impacto positivo tanto de características organizacionais (salários e benefícios), quanto de aspectos do contexto do trabalho (relacionamento e comunicação entre supervisores e empregados). Uma explicação plausível seria a de que, segundo a Teoria dos Eventos Afetivos (Weiss \& Cropanzano, 1996), os estados emocionais se constituem em elementos de ligação entre o ambiente laboral e as atitudes e sentimentos a ele dirigidos. Nesse sentido, certas características do ambiente de trabalho conduzem à vivência de emoções específicas (reações afetivas), as quais, se vivenciadas regularmente por certo tempo, acabarão por influenciar as atitudes e sentimentos sobre o trabalho e a organização. Os afetos positivos dirigidos ao trabalho estariam, assim, sob a influência mais direta do contexto laboral, razão pela qual poderiam estar sendo mais impactados pelas diferentes características de tal contexto, como é o caso, por exemplo, das oportunidades de uso e desenvolvimento das próprias competências, dos salários e benefícios e do relacionamento e comunicação entre supervisores e empregados.

Tomados em conjunto, os achados ora obtidos podem ser também interpretados à luz do Modelo de Demandas 
e Recursos do Trabalho (Bakker \& Demerouti, 2007), de acordo com o qual os aspectos psicossociais do trabalho podem ser alocados em duas principais categorias: demandas do trabalho e recursos do trabalho. As demandas do trabalho dizem respeito aos fenômenos do contexto laboral que exigem esforço físico ou psicológico do trabalhador e, consequentemente, implicam em custos fisiológicos e psicológicos. Os recursos do trabalho, por outro lado, referem-se às características das situações de trabalho que reduzem as demandas laborais e os custos a elas associados, em razão de se mostrarem funcionais para o alcance de metas e estimularem a aprendizagem e desenvolvimento pessoal. Tais recursos revestem-se, portanto, de caráter motivacional, em virtude de possibilitarem a satisfação de necessidades humanas básicas e o crescimento pessoal. Com o apoio de tal modelo teórico, é plausível afirmar que as oportunidades de uso e desenvolvimento das próprias competências, o relacionamento e a comunicação entre supervisores e empregados e os salários e benefícios, na amostra pesquisada, estão provavelmente funcionando como recursos do trabalho que, por sua natureza motivacional, estariam produzindo um impacto positivo em certos indicadores da qualidade de vida e bem-estar no trabalho dos empregados.

\section{Considerações Finais}

Os achados atuais permitem a formulação de sugestões sobre decisões estratégicas que poderão contribuir para o incremento da qualidade de vida e bem-estar dos empregados da empresa investigada. Nesse sentido, os programas de qualidade de vida até aqui desenvolvidos pela empresa têm se utilizado tão somente de estratégias focadas no indivíduo, as quais se destinam basicamente à modificação de cognições e comportamentos relacionados à saúde e bem-estar dos trabalhadores. Tais programas têm, porém, recebido críticas (Cooper, Dewe, \& O’Driscoll, 2001) associadas ao fato de colocarem a principal responsabilidade sobre a qualidade de vida e bem-estar no trabalho no próprio empregado (prevenção secundária) e não na organização (prevenção primária). De modo consoante com essas críticas, os resultados da presente pesquisa evidenciaram que certas dimensões presentes no contexto da organização e do trabalho (oportunidades de uso e desenvolvimento das próprias competências; relacionamento e comunicação entre supervisores e empregados; salários e benefícios) se constituem em importantes preditores do comprometimento organizacional afetivo, da satisfação no trabalho e dos afetos que os empregados dirigem a seu trabalho. Seria, assim, interessante que o Programa de Qualidade de Vida da empresa procurasse também adotar medidas voltadas à intervenção nessas dimensões do contexto organizacional e do trabalho, e não apenas nos indivíduos, como forma de melhorar a qualidade de vida e bem-estar de seus funcionários.

No que tange às limitações da presente pesquisa, cumpre registrar o fato de ela ter se baseado em um desenho metodológico de natureza correlacional. Consequentemente, não é possível o estabelecimento de relações causais entre os fenômenos investigados, na medida em que outros fatores não controlados podem ter concorrido para os efeitos observados.
Outrossim, a investigação se realizou em uma única organização e adotou uma amostra não aleatória de conveniência, o que limita suas possibilidades de generalização. Por fim, ela se revestiu de caráter exploratório, em função da ausência de um modelo teórico mais sólido, que permitisse a derivação de hipóteses a respeito das relações investigadas.

Desse modo, uma agenda de pesquisas voltadas ao prosseguimento de investigações na área de qualidade de vida e bem-estar no trabalho deveria incluir a realização de estudos futuros que se detivessem na análise de organizações de ramos distintos da aqui estudada, bem como no uso de outras dimensões e indicadores do fenômeno investigado. Seria, assim, interessante verificar, por exemplo, o impacto de dimensões como a cultura da organização, sua imagem perante a sociedade e o equilíbrio trabalho-família, em diferentes indicadores da qualidade de vida e bem-estar no trabalho. Além disso, aspectos aqui não contemplados, como os comportamentos retaliatórios, a ausência de exaustão emocional e a falta de despersonalização poderiam também ser adotados como indicadores da qualidade de vida e bem-estar no trabalho em estudos futuros. A realização dessas e outras investigações, com o apoio de modelos teóricos mais sólidos, poderá indubitavelmente contribuir para que as organizações conscientizem-se cada vez mais da importância de se adotar a qualidade de vida e bem-estar no trabalho como fator estratégico de gestão.

\section{Referências}

Asfora, S. C., \& Dias, M. R. C. (2006). Modelo de qualidade de vida no trabalho para a polícia militar de Pernambuco. Revista Eletrônica de Administração, 12, 1-26. Retrieved from http:// read.adm.ufrgs.br/edicoes/pdf/artigo_390.pdf.

Bakker, A. B., \& Demerouti, E. (2007). The job demands-resources model: State of the art. Journal of Managerial Psychology, 22, 309-328.

Bowditch, J. L., \& Buono, A. F. (2002). Elementos de comportamento organizacional. São Paulo, SP: Thomson Pioneira.

Brief, A. P., \& Roberson, L. (1989). Job attitude organization: An exploratory study. Journal of Applied Psychology, 19, 717-727.

Carvalho, I. S (2007). Clima psicológico como preditor da saúde e do bem-estar de profissionais de saúde em contexto hospitalar. Psicologia, 21, 27-58.

Chiuzi, M. R. (2006). As dimensões da organização positiva e seus impactos sobre o bem-estar dos trabalhadores. Dissertação de Mestrado não-Publicada, Programa de Pós-Graduação em Psicologia da Saúde, Universidade Metodista de São Paulo, São Bernardo do Campo.

Cohen-Charash, Y., \& Spector, P. E. (2001). The role of justice in organizations: A meta-analysis. Organizational Behavior and Human Decision Processes, 86, 278-321.

Cooper, C. L., Dewe, P. J., \& O’Driscoll, M. P. (2001). Organizational stress: A review and critique of theory, research, and applications. Thousand Oaks, CA: Sage.

Considini, G., \& Callus, R.(2002). The quality of work life of Australian employees: The development of an index (Working Paper 73). Sidney: University of Sydney. Retrieved from http:// www.davidkoutsoukis.com/documents/TheQualityOfWorkLi feOfAustralian\% 20Employees.pdf 
Covacs, J. M. (2006). Bem-estar no trabalho: O impacto dos valores organizacionais, percepção de suporte organizacional e percepção de justiça. Dissertação de Mestrado não-Publicada, Programa de Pós-Graduação em Psicologia da Saúde, Universidade Metodista de São Paulo, São Bernardo do Campo.

Ferreira, M. C., Assmar, E. M., Braga, L. L., Souto, S. O., Rocha, P. M., \& Lamastra, G. P. (2002). Adaptação Brasileira de uma Escala Tridimensional para Avaliação do Comprometimento Organizacional [Resumo]. In Conselho Federal de Psicologia (Ed..), Anais do I Congresso Brasileiro Psicologia: Ciência e Profissão. Brasília, DF: CFP. Retrieved from http://www. cienciaeprofissao.com.br/congre/downloads.asp

Ferreira, M. C., Silva, A. P., Fernandes, H., \& Pacheco, S. (2008). Desenvolvimento e validação de uma escala de afetos no trabalho. Avaliação Psicológica, 7, 143-150.

González, P., Peiró, J. M., \& Bravo, M. J. (1996). Calidad de vida laboral. In J. M. Peiró, \& F. Prieto (Eds.), Tratado de psicología del trabajo: Volumen II. Aspectos psicosociales del trabajo (pp. 161-186). Madrid, Spain: Síntesis.

Hackman, R. J., \& Oldham R. G. (1975). Development of job diagnostic survey. Journal of Applied Psychology, 60,159-170.

Huang. T. C, Lawler, J., \& Yi-Lei, C. (2007). The effects of quality of work life on commitment and turnover intention. Social Behavior and Personality, 35, 733-730.

Leite Filho, C. A., \& Almeida, S. T (2005). Qualidade de vida no trabalho: Uma análise da percepção dos servidores da FUNASA/PB. In Universidade Estadual Paulista (Ed.), Anais do XII Simpósio de Engenharia de Produção. Bauru, SP: UNESP. Retrieved from http://www.simpep.feb.unesp.br/ anais/anais_12/copiar.php?arquivo=Filho_caplf_qualidade de vida no trabalho.pdf

Lewchuck, W., Stewart, P., \& Yates, C. (2001). Quality of working life in the automobile industry: A Canada-UK comparative study. New Technology, Work \& Employment, 16, 72-87.

Locke, E. A. (1976). The nature and causes of job satisfaction. In M. D. Dunnette (Ed.), Handbook of industrial and organizational psychology (pp. 1297-1249). Chicago, IL: Rand McNally.

Meyer, J. P., \& Allen, N. J. (1997). Commitment in the workplace: Theory, research, and application. London, England: Sage.

Nadler, D. A., \& Lawler III, E. E. (1983). Quality of work life: Perspectives and directions. Organizational Dynamics, 11, 20-30.

Paz, M. G. T. (2004). Poder e saúde organizacional. In A. Tamayo (Ed.), Cultura e saúde nas organizações (pp. 127-154). Porto Alegre, RS: Artmed.
Pizzoli, L. M. L. (2005). Qualidade de vida no trabalho: Um estudo de caso das enfermeiras do Hospital Heliópolis. Revista Ciência e Saúde Coletiva, 4, 1055-1062.

Schouteten, R. L. J., \& Witte, M. C. (1999). The quality of working life revisited: The changing interface between work and family (Research Report). Groningen: University of Groningen. Retrieved from http://som.eldoc.ub.rug.nl/FILES/ reports/1995-1999/ themeA/1999/99A61/99a61.pdf

Silva, A. P. C., \& Ferreira, M. C. (2009). Escala de Satisfação Geral no Trabalho. [Resumo ]. In Instituto Brasileiro de Avaliação Psicológica (Ed.), Anais do IV Congresso Brasileiro de Avaliação Psicológica (p. 246). Campinas, SP: IBAP.

Tabachnick, B. G., \& Fidell, L. (2001). Using multivariate statistics. Boston, MA: Allyn and Bacon.

Tolfo, S. R., \& Piccini, V. C. (2001). As melhores empresas para se trabalhar no Brasil e a qualidade de vida no trabalho: Disjunções entre a teoria e a prática. Revista de Administração Contemporânea, 5, 165-193.

van Horn, J. E., Taris, T. W., Schaufeli, W. B., \& Scheurs, P. J. (2004). The structure of occupational well-being: A study among Dutch teachers. Journal of Occupational and Organizational Psychology, 77, 365-375.

Walton, R. E. (1973). Quality of working life: What is it? Slow Management, 15, 11-21.

Warr, P. (1987). Work, unemployment and mental health. Oxford, England: Oxford University Press.

Weiss, H. M., \& Cropanzano, R. (1996). Affective events theory: A theoretical discussion of the structure, causes, and consequences of affective experiences at work. Research in Organizational Behavior, 18, 1-74.

Westley, W. A. (1979). Problems and solutions in the quality of working life. Human Relations, 32, 113-123.

Wilson, M. G., DeJoy, D. M., Vandenberg, R. J., Richardson, H. A., \& McGrath, A. L. (2004). Work characteristics and employee health and well-being: Test of a model of healthy work organization. Journal of Occupational and Organizational Psychology, 77, 565-588.

Recebido em 12.12.2010

Primeira decisão editorial em 30.01.2013

Versão final em 19.03.2013

Aceito em 25.03.2013 